\title{
Combination of catheter ablation for non-valvular atrial fibrillation and left atrial appendage occlusion in a single procedure
}

\author{
XUEXUN LI, JIANPING LI, HONGXIA CHU, LIHONG WANG, LEI SHI, \\ GUANGQIANG WANG and XIAOFEI WANG
}

Department of Cardiology, Yantai Yuhuangding Hospital, Yantai, Shandong 264000, P.R. China

Received October 29, 2017; Accepted May 11, 2018

DOI: $10.3892 /$ etm.2018.6358

\begin{abstract}
Patients with atrial fibrillation (AF) have an increased risk of stroke and systemic embolism. Catheter ablation (CA) is increasingly applied for the treatment for drug-refractory AF; however, its long-term success rate is $<50 \%$. It has been proved that percutaneous left atrial appendage occlusion (LAAO) exerts the same efficacy as novel oral anti-coagulants [(N) OACs] in reducing thromboembolic events. The present study investigated whether a combined procedure of AF ablation and LAAO may be feasible and efficacious. CA was performed for patients with $\mathrm{AF}$ and a high risk of stroke according to their $\mathrm{CHADS}_{2}$ or $\mathrm{CHA}_{2} \mathrm{DS}_{2}$-VASc score, and LAAO was performed using the Watchman device. A total of 25 patients $(40 \%$ females; mean age, $64.2 \pm 3.5$ years) who were treated between July 2016 and June 2017 were included in the present study. The median CHA2DS2-VASc score was 4.5 (range, 2-6) and the median HAS-BLED score was 3.17 (range, 1-7). Successful CA and LAAO were performed in $100 \%$ of cases. All patients met the criteria for successful LAAO. At the 6-month follow-up, complete sealing of the LAA was achieved in 23 patients (92\%), while a minimal residual flow $(<5 \mathrm{~mm})$ was detected in 2 patients $(8 \%)$. In 24 patients $(96 \%)$, the administration of $(\mathrm{N})$ OACs was terminated and aspirin administration was initiated at the 6-month follow-up. (N)OAC treatment was maintained in 1 patient (4\%) on the basis of transient ischemic attack. During the 6-month follow-up period, 3 patients who had a recurrence of $\mathrm{AF}$ received a repeated ablation. In conclusion, the combination of CA and LAAO in a single procedure is feasible, safe and efficacious for patients with non-valvular AF at a high risk of stroke, and a contraindication regarding the use of (N)OACs.
\end{abstract}

Correspondence to: Dr Jianping Li, Department of Cardiology, Yantai Yuhuangding Hospital, 20 Yuhuangdingdong Road, Zhifu, Yantai, Shandong 264000, P.R. China

E-mail: lijianpingyt@qq.com

Key words: catheter ablation, atrial fibrillation, left atrial appendage occlusion, oral anti-coagulation, stroke prevention

\section{Introduction}

As a common type of arrhythmia, atrial fibrillation (AF) occurs in $1-2 \%$ of individuals (1-3). In patients with non-valvular $\mathrm{AF}$, the risk of ischemic stroke and systemic embolism is 5 -fold increased compared with that in the general population (4), leading to a yearly incidence of ischemic stroke of $5 \%$ in patients with non-valvular AF and $15 \%$ in high-risk patients (5). In patients with AF, stroke is mainly caused by atrial thrombi formed in the left atrial appendage (LAA), and according to a previous study, $90 \%$ of the thrombi formed in patients with AF were arising from the LAA (6). According to the European Society of Cardiology (ESC) guidelines, all AF patients with a high risk of thrombosis are required to take oral anti-coagulants (OACs) to prevent thromboembolic events (7). Although it is well established that patients with AF at a high risk of stroke benefit from warfarin or the recently introduced novel (N)OACs, these medications have several disadvantages, including severe hemorrhage and non-compliance (8-10). While catheter ablation (CA) for the treatment of AF is recommended by the 2016 ESC guidelines and is efficacious in rhythm control, its long-term efficacy is poor, and its role in stroke prevention remains unproven. Randomized clinical trials have demonstrated that percutaneous mechanical LAA occlusion (LAAO) is effective in preventing thromboembolism in AF patients (11-13). Combining CA and LAAO in a single procedure is an efficacious strategy for the treatment of patients at high risk of stroke. The present study reported on the rationale and feasibility of the technique of combining of $\mathrm{CA}$ and percutaneous LAAO in a single procedure, which is a novel procedure compared to various previous approaches, providing an optimized surgical route.

\section{Materials and methods}

Study group. Patients aged $\geq 18$ years with documented paroxysmal or (longstanding) persistent, non-valvular AF, a $\mathrm{CHADS}_{2}$ score (14) of $\geq 1$ and/or a $\mathrm{CHA}_{2} \mathrm{DS}_{2}$-VASc score (15) $\geq 2$, a HAS-BLED score $(16) \geq 1$, who were subjected to CA and percutaneous LAAO in a single procedure at Yantai Yuhuangding Hospital (Yantai, China) between July 2016 and June 2017 were included in the present study (Table I). 
Written informed consent was obtained from all participants included in the study. The Ethics Committee of Yantai Yuhuangding Hospital (Yantai, China) approved the protocol of the present study.

Pre-procedure preparation. Patients with an international normalized ratio of 2.0-3.0 were required to take vitamin $\mathrm{K}$ antagonist prior to the procedure or to take (N)OACs, which was discontinued from the day of the procedure. Prior to the procedure, a transesophageal echocardiogram (TEE) was recorded to exclude thrombi within the LAA, assess the anatomy of the LAA and to determine the appropriate occlusion device size (Fig. 1). All of the procedures were performed without general anesthesia.

Electrophysiological and CA procedure in AF patients. Local anesthesia was performed by administration of lidocaine in the groin and left subclavian region, and fentanyl was given as an analgesic. Through the left subclavian venous access, a decapolar catheter was placed in the coronary vein. Two transseptal punctures were performed through the right femoral vein using a Brockenbrough (BRK) needle (Baylis Medical Company Inc., Sainy-Laurent, Canada) to ensure co-axial alignment with the appendage. One inferior and posterior transseptal puncture was required. An unfractioned heparin bolus of 7,500 international units (IU) was given after transseptal puncture, and thereafter 1,000 IU were administered at 1-h intervals. Angiography of LAA and pulmonary veins (PVs) was performed via the sheath. A circular mapping catheter (Lasso NAV; Biosense Webster; Johnson \& Johnson, New Brunswick, NJ, USA) was used to map PV potentials and construct the model of the left atrium and PVs. PV isolation was guided by a 3-dimensional mapping system (CARTO3 system; Biosense Webster; Johnson \& Johnson) and performed point-by-point using a ThermoCool Smart Touch Catheter (Biosense Webster; Johnson \& Johnson) with the power and temperature limited to $30-35 \mathrm{~W}$ and $43^{\circ} \mathrm{C}$, respectively. Bidirectional conduction block between the LA and PVs was the end-point of catheter ablation. Only PV isolation was performed for patients with paroxysmal AF. A roofline was also performed for patients with persistent AF (Fig. 2).

LAAO with Watchman device. Immediately after the ablation procedure, the implantation of a Watchman device was performed by using fluoroscopy and TEE guidance.

Cefazolin sodium pentahydrate was administered as a prophylactic antibiotic at the end of the ablation procedure. A Watchman device (Boston Scientific, Marlborough, MA, USA) was then implanted using the following procedure: A $14 \mathrm{~F}$ transseptal access sheath for delivering the pigtail catheter replaced the more inferior and posterior transseptal sheath. A pigtail catheter was positioned in the LAA to perform an angiography of the LAA at a right anterior oblique angle of $20-30^{\circ}$ and a caudal angle $20-30^{\circ}$, delineating the shape and size of the LAA (Fig. 3). The device size was selected to be $10-20 \%$ larger than the largest diameter of the LAA measured by angiography and TEE guidance was applied for stable positioning.

The access sheath for delivering the Watchman device was carefully advanced over the pigtail catheter. The pigtail

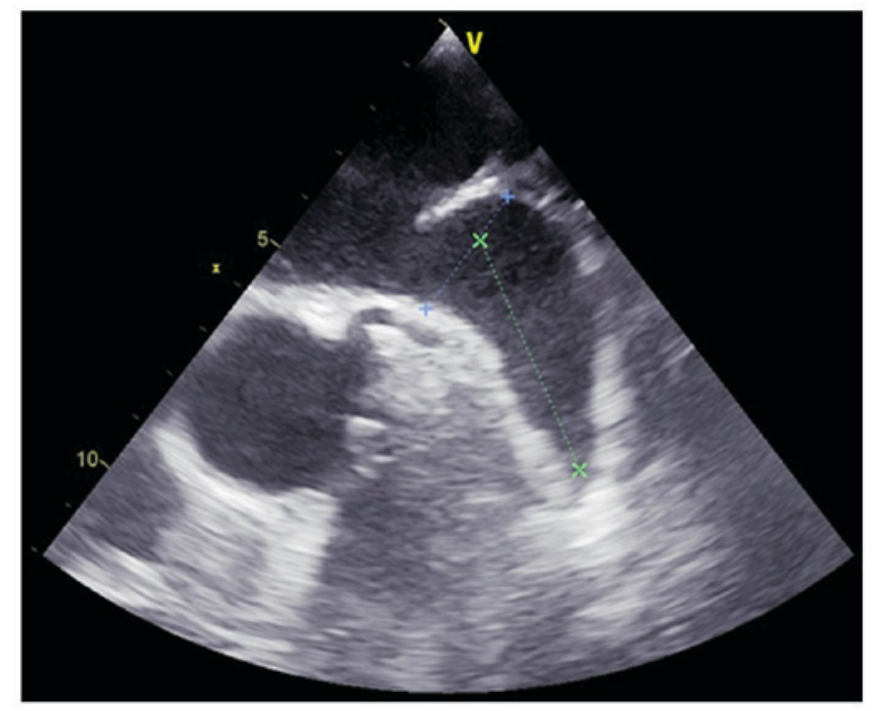

Figure 1. Transesophageal echocardiogram of the LAA to document the absence of thrombi within the LAA and to assess features and type of LAA. LAA, left atrial appendage.

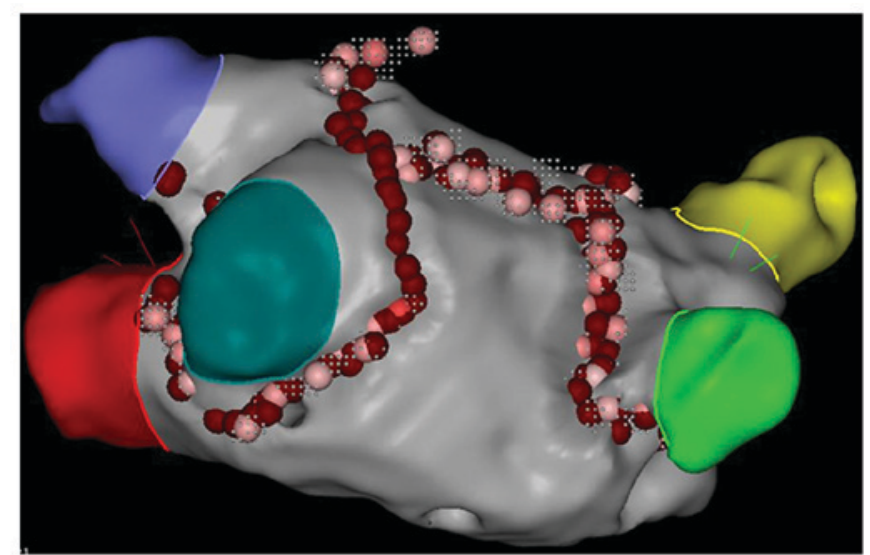

Figure 2. Schematic of the atrial fibrillation ablation. Electrophysiological and atrial fibrillation catheter ablation procedure visualized using Carto 3 . Gray represents the left atrium, green, yellow and purple represent pulmonary veins and red represents the left atrial appendage.

was then slowly removed. The device was deployed by retraction of the access sheath. Before the device was released, it was ensured that it was properly positioned, with minimal (leak of $\leq 5 \mathrm{~mm}$ ) or no residual lateral flow past the device (confirmed by angiography and TEE; Fig. 4), and a sustained tug test for stability was performed.

Statistical analysis. The patients' characteristics were reported by descriptive statistics. The results were expressed as the mean \pm standard deviation or the median (25-75th percentiles). Categorical variables were reported as n (\%). All statistical data were analyzed by using SPSS software 19.0 (IBM Corp., Armonk, NY, USA).

\section{Results}

Between July 2016 and June 2017, all 25 patients (40\% females; mean age, $64.2 \pm 3.5$ years) successfully underwent a 
A

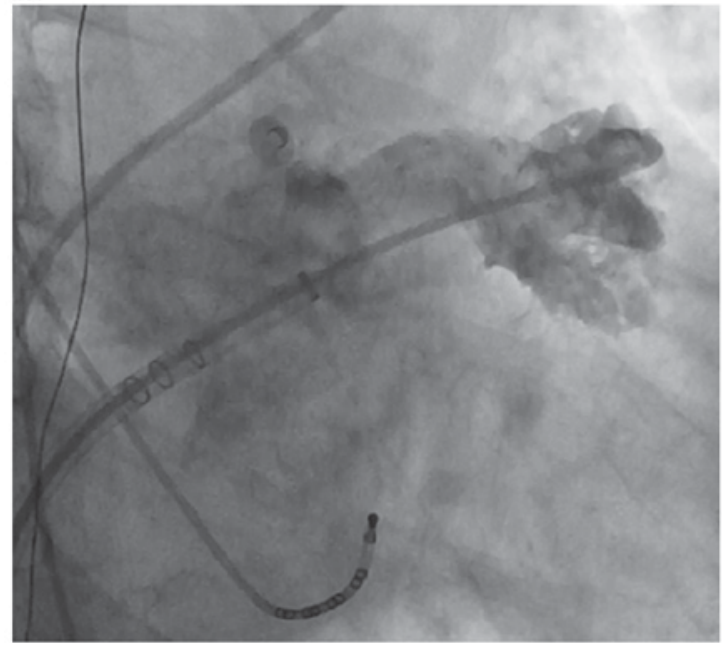

B

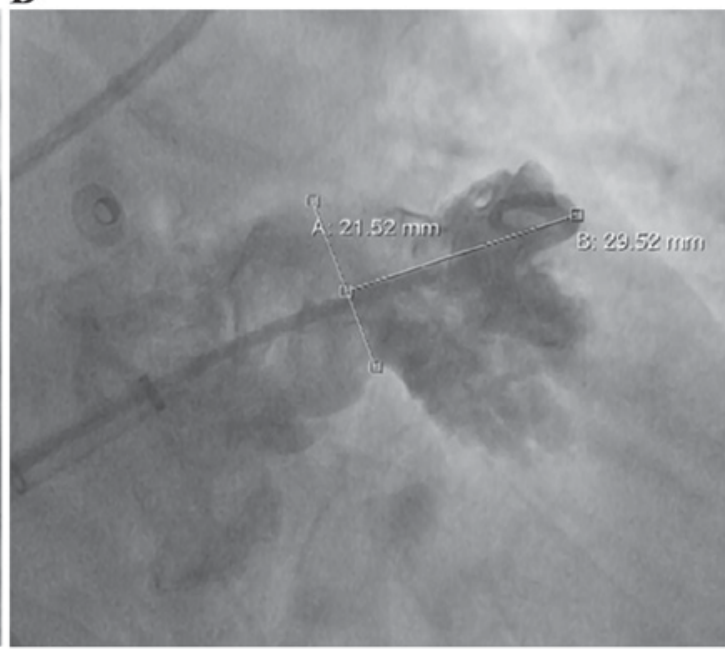

Figure 3. Angiogram and measurements of the LAA. (A) Angiogram of the LAA at a right anterior oblique of $30^{\circ}$ and caudal $20^{\circ}$. (B) Angiographic measurements of the length and width of the LAA for the selection of an appropriately sized Watchman device. LAA, left atrial appendage.

A

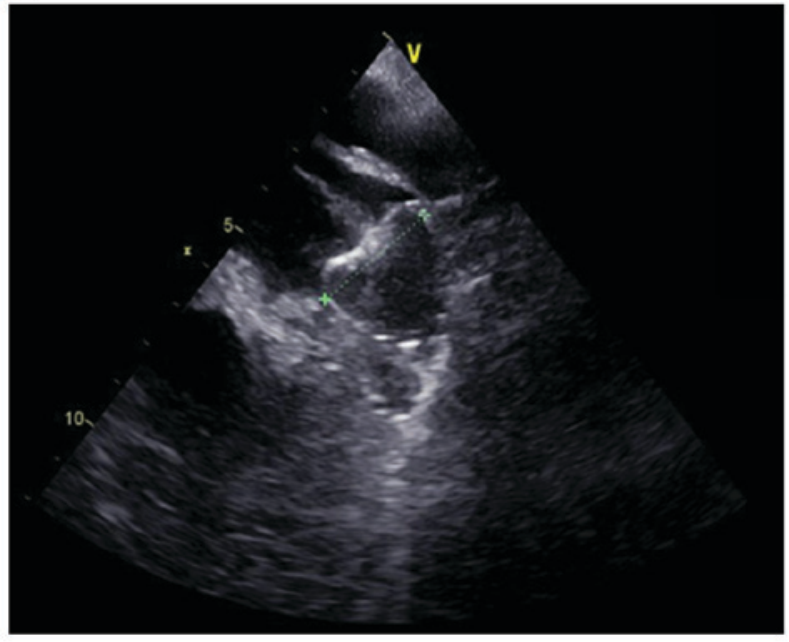

B

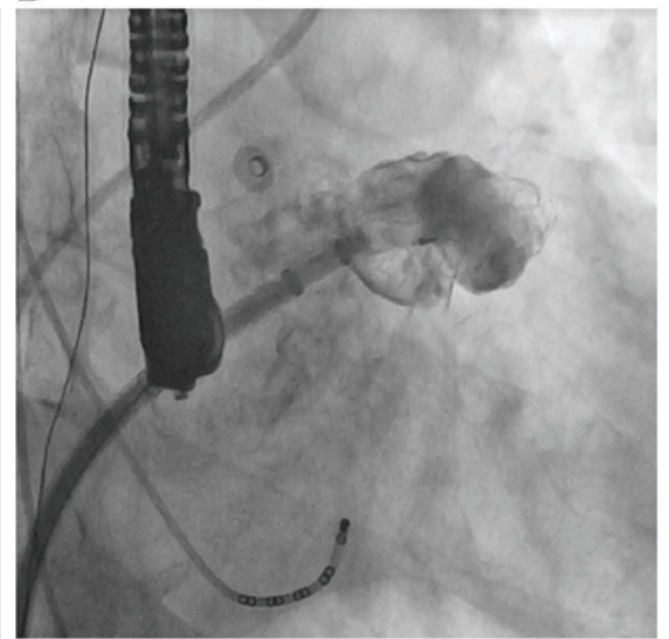

Figure 4. Evaluation of the LAA following Watchman deployment. (A) Echocardiographic evaluation of the LAA. (B) Immediate follow-up angiogram of the LAA after left atrial occlusion using a Watchman device. LAA, left atrial appendage.

combination of CA and LAA occlusion with Watchman device (short-term success rate, $100 \%$ ). In 1 patient, due to the large residual lateral flow (leak of $>5 \mathrm{~mm}$ ), the device required replacing with a larger-diameter one, which was successfully deployed in this second procedure. The LAAO procedure was therefore completed using a mean of $1.04 \pm 0.20$ devices per patient in the present cohort. After implantation, 3 patients had a small peri-device leak $(\leq 5 \mathrm{~mm})$, while complete closure of the LAA was achieved in all other cases. The median time for the combined procedure was $185.58 \mathrm{~min}$ (85.67 $\mathrm{min}$ for LAAO; Table II). No serious complications occurred during the procedure, and afterwards, only 2 patients had minor complications, including a slightly elevated temperature and a small groin hematoma, and no intervention was performed. No serious peri-procedural complications, including cardiac tamponade, dislodgement of the LAA closure, thrombus formation on the Watchman device and coronary artery air embolism occurred in any of the patients.
On the day after the procedure, all patients were discharged from hospital (Table III). The median hospital stay was 7.67 days (range, 2-13 days).

Follow-up. All of the 25 patients (100\%) underwent TEE at 60 days after the procedure and an optimal sealing performance of the LAA was observed in $92 \%$ of the cases. Complete sealing of the LAA was achieved in 23 patients (92\%) at the 6-month follow-up. A minimal residual flow (leak size, $<5 \mathrm{~mm}$ ) was detected in 2 patients (8\%). In 24 patients (96\%), the administration of (N)OACs was discontinued and aspirin treatment was initiated at the 6-month follow-up. (N)OACs treatment was maintained in 1 patient $(4 \%)$ on the basis of transient ischemic attack (Table IV). During the 6-month follow-up, 3 patients who had a recurrence of AF received a repeated ablation. In this second ablation, the Watchman device was stable and did not interfere with the procedure. Furthermore, no thrombus formation on the device was detected during the follow-up. Prior to 
Table I. Baseline characteristics of the study population $(n=25)$.

\begin{tabular}{lc}
\hline Characteristics & Value \\
\hline Mean age (years) & $64.2 \pm 3.5$ \\
Females & $10(40)$ \\
Hypertension & $18(72)$ \\
Type of AF & \\
Paroxysmal & $3(12)$ \\
Persistent & $8(32)$ \\
Long-standing persistent & $14(56)$ \\
CHADS2 score & \\
1 & $0(0)$ \\
2 & $3(12)$ \\
3 & $8(32)$ \\
4 & $11(44)$ \\
5 & $3(12)$ \\
CHA2DS2-VASc score & $4.5(2-6)$ \\
HAS-BLED score & $3.17(1-7)$ \\
Drug use & \\
Vitamin K antagonist & $14(56)$ \\
NOAC & $9(36)$ \\
Aspirin & $2(8)$ \\
Stroke during use of (N)OAC & $19(76)$ \\
\hline Values are expressed as the mean \pm standard deviation, n $(\%)$ or the \\
oral anti-coagulant. & \\
\hline & \\
\hline & \\
&
\end{tabular}

the paper being finished, a 1-year follow-up was performed for 18 patients (Table V). During the 1-year follow-up, 17 patients (95\%) achieved a complete sealing and only 1 patient $(5 \%)$ had minimal residual flow $(<2 \mathrm{~mm})$. The NOACs was interrupted in all patients and aspirin was taken. No mortality, stroke or transient ischemic events occurred. A total of 4 patients (22\%) who had a recurrence of AF received a redo-ablation successfully.

\section{Discussion}

The present study reports that the combination of LAAO and $\mathrm{CA}$ is a feasible and safe strategy for the treatment of AF in patients at high risk of stroke.

The Watchman device has been proved to be safe and effective in numerous randomized clinical trials. A previous multicenter randomized clinical trial, the 'PROETCT AF' trial, evaluated the efficacy and safety of LAAO with a Watchman device compared with warfarin treatment (17). This trial reported that LAAO with the Watchman device was not inferior compared with standard warfarin therapy in patients with non-valvular AF.

Furthermore, the 'PREVAIL' trial (18) proved that compared with the PROETCT AF study, complications associated with the LAAO procedure were infrequent, providing a significant improvement. The PREVAIL trial also indicated that LAAO with the Watchman device for the prevention of stroke was not inferior to standard warfarin therapy.
Table II. Procedural characteristics in the study population $(n=25)$.

\begin{tabular}{lc}
\hline Characteristics & Value \\
\hline Successful implantation of LAA & $25(100)$ \\
occlusion device & \\
LAA measurements (mm) & \\
Width & $28.76(21.4-31.9)$ \\
Length & $30.98(26.29-34.1)$ \\
Morphology type of LAA & \\
Chicken wing & $5(20)$ \\
Cauliflower & $14(56)$ \\
Wind sock & $6(24)$ \\
Device size (mm) & $4(16)$ \\
27 & $14(56)$ \\
30 & $7(28)$ \\
33 & $85.67(60-120)$ \\
LAA occlusion time (min) & $185.58(123-295)$ \\
Total procedural time (min) & $162(80-260)$ \\
Total contrast dose (ml) & $1.04 \pm 0.20$ \\
Mean no. of devices deployed & \\
per patient & $7.67(2-13)$ \\
Hospitalization time (days) & \\
\hline
\end{tabular}

Values are expressed as $\mathrm{n}(\%)$ or the median (25-75th percentiles). LAA, left atrial appendage.

Alli et al (19), performed a quality of life (QOL) assessment in the cohort of the PROTECT AF trial, revealing that in non-valvular AF patients treated with LAAO with the Watchman device, the QOL was improved compared to that in patients treated with warfarin.

CA is a well-established treatment to prevent recurrent AF $(20,21)$, and in maintaining the sinus rhythm, it is more effective, while the complication rate is similar compared with that associated with anti-arrhythmic drugs $(22,23)$. The optimal surgical outcome for CA is complete bidirectional conduction block between the LA and PVs (24-26), which is achieved by lesions encircling PVs caused by radiofrequency ablation or cryoballoon ablation $(27,28)$. Reynolds et al (29) reported that the risk of stroke and transient ischemic attack is decreased more significantly in patients treated with ablation than in those receiving anti-arrhythmic drug therapy. The efficacy of the hybrid procedure of CA and LAAO with the Watchman device to maintain the sinus rhythm and prevent stroke in patients with AF is supported by the data of previous studies $(30,31)$. Certain studies reasoned that the longer duration of the procedure and fluoroscopy, as well as the application of general anesthesia are disadvantages of the combined procedure $(30,32)$. In the present study, all of the procedures were performed under local anesthesia for the first time. In the present cohort, the Watchman device was successfully implanted in $96 \%$ of patients under local anesthesia on the first attempt.

Apart from the abovementioned limited single-center studies, a consensus statement from the European Heart Rhythm Association/European Association of Percutaneous 
Table III. Procedure-associated complications and postprocedure TEE results.

\begin{tabular}{lc}
\hline Characteristics & Value \\
\hline Complications & \\
Catheter thrombus & $0(0)$ \\
Hematoma & $1(4)$ \\
Pericardial effusion & $0(0)$ \\
Post-procedure TEE observations & \\
Successful implantation & $25(100)$ \\
Minimal residual flow & $3(12)$ \\
Hospitalization time (days) & $7.67(2-13)$ \\
\hline
\end{tabular}

Values are expressed as $\mathrm{n}(\%)$ or the median (25-75th percentiles). LAA, left atrial appendage; TEE, transesophageal echocardiography.

Table IV. Characteristics of the patients $(n=25)$ at 6 -month follow-up.

\begin{tabular}{lc}
\hline Characteristics & Value \\
\hline TEE observations & \\
Minimal residual flow & $2(8)$ \\
Device embolism & $0(0)$ \\
Thrombus on device & $0(0)$ \\
No atrial fibrillation recurrent & $11(44)$ \\
(N)OAC use & $1(4)$ \\
Repeated ablation & $2(12)$ \\
Complications during follow-up & \\
Stroke & $0(0)$ \\
Transient ischemic attack & $1(4)$ \\
Major bleeding & $0(0)$ \\
\hline
\end{tabular}

Values are expressed as n (\%). TEE, transesophageal echocardiography; (N)OAC, novel oral anti-coagulant.

Cardiovascular Interventions (33) suggests that the hybrid procedure of CA and LAAO is beneficial for patients with a contraindication for OACs and a high risk of thromboembolic events.

The feasibility and techniques of combining CA and LAAO with the Watchman device in a single procedure have been reported by few studies $(30,31)$. The avoidance of a second vascular access and transseptal puncture may make the combined strategy safer. It is important to note that a combined procedure of Watchman placement and CA does not interfere with the electrical isolation of the LAA. Di Biase et al (34) revealed that in $27 \%$ of patients with recurrent AF after initial ablation, foci arising from the LAA were observed, and electrical isolation of the LAA should ideally be performed in these patients. LAA may be more thrombogenic due to LAA stasis caused by electrical isolation of the LAA. LAAO may be particularly beneficial for these patients.
Table V. Characteristics at 1-year follow-up $(n=18)$.

\begin{tabular}{ll}
\hline Characteristics & Value \\
\hline TEE observations & \\
Minimal residual flow & $1(5)$ \\
Device embolism & $0(0)$ \\
Thrombus on device & $0(0)$ \\
No atrial fibrillation recurrent & $9(50)$ \\
(N)OAC use & $0(0)$ \\
Redo ablation & $4(22)$
\end{tabular}

No causes of mortality, stroke, transient ischemic attack or major bleeding occurred. Values are expressed as n (\%). TEE, transesophageal echocardiography; (N)OAC, novel oral anti-coagulant.

In the present study, $100.0 \%$ of the patients had a successful occlusion, and $12.0 \%$ (3/25) had small residual leak immediately after the release of the device. During the 6-months follow-up, the stroke rate in the present study was 0 . However, 1 patient had a transient ischemic attack at 3 months after the procedure. Device-associated thrombus formation remains a concern, but was not observed in the present study. A limitation of the present study is that there is no other treatment that the group was compared with.

In conclusion, the present study indicated that combination of CA and LAAO in a single procedure is feasible, safe and efficacious for patients with non-valvular AF at a high risk of stroke, and a contraindication regarding the use of (N)OACs.

\section{Acknowledgements}

Not applicable.

Funding

No funding was received.

\section{Availability of data and materials}

The datasets used and/or analyzed during the current study are available from the corresponding author on reasonable request.

\section{Authors' contributions}

XL and JL contributed to the conception and design of the study and wrote this manuscript. HC, LW and LS collected and analyzed clinical data. GW and XW contributed to the patient follow-ups and revised the manuscript for intellectual content. The final version of the manuscript has been read and approved by all authors, and each author believes that the manuscript represents honest work.

\section{Ethical approval and consent to participate}

Written informed consent was obtained from all participants included in the study. The Ethics Committee of Yantai 
Yuhuangding Hospital (Yantai, China) approved the protocol of the present study.

\section{Patient consent for publication}

Not applicable.

\section{Competing interests}

The authors declare that they have no competing interests.

\section{References}

1. Camm AJ, Kirchhof P, Lip GY, Schotten U, Savelieva I, Ernst S, Van Gelder IC, Al-Attar N, Hindricks G, Prendergast B, et al Guidelines for the management of atrial fibrillation: The Task Force for the Management of Atrial Fibrillation of the European Society of Cardiology (ESC). Europace 12: 1360-1420, 2010.

2. Go AS, Hylek EM, Phillips KA, Chang Y, Henault LE, Selby JV and Singer DE: Prevalence of diagnosed atrial fibrillation in adults: National implications for rhythm management and stroke prevention: The AnTicoagulation and risk factors in atrial fibrillation (ATRIA) study. JAMA 285: 2370-2375, 2001.

3. Stewart S, Hart CL, Hole DJ and McMurray JJ: Population prevalence, incidence, and predictors of atrial fibrillation in the Renfrew/Paisley study. Heart 86: 516-521, 2001.

4. Lloyd-Jones D, Adams R, Carnethon M, De Simone G, Ferguson TB, Flegal K, Ford E, Furie K, Go A, Greenlund K, et al: Heart disease and stroke statistics - 2009 update: A report from the American Heart Association Statistics Committee and Stroke Statistics Subcommittee. Circulation 119: 480-486, 2009.

5. Lloyd-Jones DM, Wang TJ, Leip EP, Larson MG, Levy D, Vasan RS, D'Agostino RB, Massaro JM, Beiser A, Wolf PA and Benjamin EJ: Lifetime risk for development of atrial fibrillation: The Framingham Heart Study. Circulation 110: 1042-1046, 2004.

6. Goldman ME, Pearce LA, Hart RG, Zabalgoitia M, Asinger RW, Safford R and Halperin JL: Pathophysiologic correlates of thromboembolism in nonvalvular atrial fibrillation: I. Reduced flow velocity in the left atrial appendage (The stroke prevention in atrial fibrillation (SPAF-III) study). J Am Soc Echocardiogr 12: 1080-1087, 1999.

7. Kirchhof P, Benussi S, Kotecha D, Ahlsson A, Atar D, Casadei B, Castellá M, Diener HC, Heidbuchel H, Hendriks J, et al: 2016 ESC guidelines for the management of atrial fibrillation developed in collaboration with EACTS. Rev Esp Cardiol (Engl Ed) 70: 50, 2017 (In English, Spanish).

8. Baker WL, Cios DA, Sander SD and Coleman CI: Meta-analysis to assess the quality of warfarin control in atrial fibrillation patients in the United States. J Manag Care Pharm 15: 244-252, 2009.

9. Hylek EM, Evans-Molina C, Shea C, Henault LE and Regan S: Major hemorrhage and tolerability of warfarin in the first year of therapy among elderly patients with atrial fibrillation. Circulation 115: 2689-2696, 2007.

10. Lip GY, Andreotti F, Fauchier L, Huber K, Hylek E, Knight E, Lane DA, Levi M, Marin F, Palareti G, et al: Bleeding risk assessment and management in atrial fibrillation patients: A position document from the European Heart Rhythm Association, endorsed by the European Society of Cardiology Working Group on Thrombosis. Europace 13: 723-746, 2011.

11. Holmes DR, Reddy VY, Turi ZG, Doshi SK, Sievert H, Buchbinder M, Mullin CM and Sick P; PROTECT AF Investigators: Percutaneous closure of the left atrial appendage versus warfarin therapy for prevention of stroke in patients with atrial fibrillation: A randomised non-inferiority trial. Lancet 374: 534-542, 2009.

12. Reddy VY, Holmes D, Doshi SK, Neuzil P and Kar S: Safety of percutaneous left atrial appendage closure: Results from the Watchman left atrial appendage system for embolic protection in patients with AF (PROTECT AF) clinical trial and the continued access registry. Circulation 123: 417-424, 2011.

13. Reddy VY, Doshi SK, Sievert H, Buchbinder M, Neuzil P, Huber K, Halperin JL and Holmes D; PROTECT AFInvestigators: Percutaneous left atrial appendage closure for stroke prophylaxis in patients with atrial fibrillation: 2.3-Year follow-up of the PROTECT AF (Watchman left atrial appendage system for embolic protection in patients with atrial fibrillation) trial. Circulation 127: 720-729, 2013.
14. Gage BF, Waterman AD, Shannon W, Boechler M, Rich MW and Radford MJ: Validation of clinical classification schemes for predicting stroke: Results from the National Registry of Atrial Fibrillation. JAMA 285: 2864-2870, 2001.

15. Lip GY, Nieuwlaat R, Pisters R, Lane DA and Crijns HJ: Refining clinical risk stratification for predicting stroke and thromboembolism in atrial fibrillation using a novel risk factor-based approach: The euro heart survey on atrial fibrillation. Chest 137: 263-272, 2010

16. Lip GY, Frison L, Halperin JL and Lane DA: Comparative validation of a novel risk score for predicting bleeding risk in anticoagulated patients with atrial fibrillation: The HAS-BLED (hypertension, abnormal renal/liver function, stroke, bleeding history or predisposition, labile INR, elderly, drugs/alcohol concomitantly) score. J Am Coll Cardiol 57: 173-180, 2011.

17. Fountain RB, Holmes DR, Chandrasekaran K, Packer D, Asirvatham S, Van Tassel R and Turi Z: The PROTECT AF (WATCHMAN Left Atrial Appendage System for Embolic PROTECTion in patients with atrial fibrillation) trial. Am Heart J 151: 956-961, 2006.

18. Belgaid DR, Khan Z, Zaidi M and Hobbs A: Prospective randomized evaluation of the watchman left atrial appendage closure device in patients with atrial fibrillation versus long-term warfarin therapy: The PREVAIL trial. Int J Cardiol 219: 177-179, 2016.

19. Alli O, Doshi S, Kar S, Reddy V, Sievert H, Mullin C, Swarup V, Whisenant B and Holmes D Jr: Quality of life assessment in the randomized PROTECT AF (percutaneous closure of the left atrial appendage versus warfarin therapy for prevention of stroke in patients with atrial fibrillation) trial of patients at risk for stroke with nonvalvular atrial fibrillation. J Am Coll Cardiol 61: 1790-1798, 2013.

20. Arbelo E, Brugada J, Hindricks G, Maggioni AP, Tavazzi L, Vardas P, Laroche C, Anselme F, Inama G, Jais P, et al: The atrial fibrillation ablation pilot study: A European Survey on Methodology and results of catheter ablation for atrial fibrillation conducted by the European Heart Rhythm Association. Eur Heart J 35: 1466-1478, 2014.

21. Calkins H, Kuck KH, Cappato R, Brugada J, Camm AJ, Chen SA, Crijns HJ, Damiano RJ Jr, Davies DW, DiMarco J, et al: 2012 HRS/EHRA/ECAS Expert Consensus Statement on Catheter and Surgical Ablation of Atrial Fibrillation: Recommendations for patient selection, procedural techniques, patient management and follow-up, definitions, endpoints, and research trial design. Europace 14: 528-606, 2012.

22. Mont L, Bisbal F, Hernández-Madrid A, Pérez-Castellano N, Viñolas X, Arenal A, Arribas F, Fernández-Lozano I, Bodegas A, Cobos A, et al: Catheter ablation vs. antiarrhythmic drug treatment of persistent atrial fibrillation: A multicentre, randomized, controlled trial (SARA study). Eur Heart J 35: 501-507, 2014.

23. Walfridsson H, Walfridsson U, Nielsen JC, Johannessen A, Raatikainen P, Janzon M, Levin LA, Aronsson M, Hindricks G, Kongstad O, et al: Radiofrequency ablation as initial therapy in paroxysmal atrial fibrillation: Results on health-related quality of life and symptom burden. The MANTRA-PAF trial. Europace 17: 215-221, 2015.

24. Kuck KH, Hoffmann BA, Ernst S, Wegscheider K, Treszl A, Metzner A, Eckardt L, Lewalter T, Breithardt G and Willems S; Gap-AF-AFNET 1 Investigators*: Impact of complete versus incomplete circumferential lines around the pulmonary veins during catheter ablation of paroxysmal atrial fibrillation: Results from the gap-atrial fibrillation-German atrial fibrillation competence network 1 trial. Circ Arrhythm Electrophysiol 9: $\mathrm{e} 003337,2016$.

25. McLellan AJ, Ling LH, Azzopardi S, Lee GA, Lee G, Kumar S, Wong MC, Walters TE, Lee JM, Looi KL, et al: A minimal or maximal ablation strategy to achieve pulmonary vein isolation for paroxysmal atrial fibrillation: A prospective multi-centre randomized controlled trial (the Minimax study). Eur Heart J 36: 1812-1821, 2015.

26. Verma A, Sanders P, Macle L, Deisenhofer I, Morillo CA, Chen J, Jiang CY, Ernst S and Mantovan R: Substrate and trigger ablation for reduction of atrial fibrillation trial-part II (STAR AF II): Design and rationale. Am Heart J 164: 1-6.e6, 2012.

27. Luik A, Radzewitz A, Kieser M, Walter M, Bramlage P, Hörmann P, Schmidt K, Horn N, Brinkmeier-Theofanopoulou M, Kunzmann K, et al: Cryoballoon versus open irrigated radiofrequency ablation in patients with paroxysmal atrial fibrillation: The prospective, randomized, controlled, noninferiority freezeaf study. Circulation 132: 1311-1319, 2015. 
28. Schmidt M, Dorwarth U, Andresen D, Brachmann J, Kuck KH, Kuniss M, Lewalter T, Spitzer S, Willems S, Senges J, et al: Cryoballoon versus RF ablation in paroxysmal atrial fibrillation: Results from the German Ablation Registry. J Cardiovasc Electrophysiol 25: 1-7, 2014.

29. Reynolds MR, Gunnarsson CL, Hunter TD, Ladapo JA, March JL, Zhang M and Hao SC: Health outcomes with catheter ablation or antiarrhythmic drug therapy in atrial fibrillation: Results of a propensity-matched analysis. Circ Cardiovasc Qual Outcomes 5: 171-181, 2012.

30. Phillips KP, Walker DT and Humphries JA: Combined catheter ablation for atrial fibrillation and Watchman ${ }^{\circledR}$ left atrial appendage occlusion procedures: Five-year experience. J Arrhythm 32: 119-126, 2016.

31. Walker DT, Humphries JA and Phillips KP: Combined catheter ablation for atrial fibrillation and watchman ${ }^{\circledR}$ left atrial appendage occlusion procedures: A single centre experience. J Atr Fibrillation 5: 687, 2012
32. Bolao IG, Calvo N, Macias A, Barba J, Salterain N, Ramos P, Ballesteros G and Neglia R: Ablation of atrial fibrillation in combination with left atrial appendage occlusion in a single procedure. Rationale and technique. J Atr Fibrillation 8: 1346, 2016.

33. Meier B, Blaauw Y, Khattab AA, Lewalter T, Sievert H, Tondo C and Glikson M: EHRA/EAPCI expert consensus statement on catheter-based left atrial appendage occlusion. EuroIntervention 10: 1109-1125, 2015.

34. Di Biase L, Burkhardt JD, Mohanty P, Sanchez J, Mohanty S, Horton R, Gallinghouse GJ, Bailey SM, Zagrodzky JD, Santangeli P, et al: Left atrial appendage: An underrecognized trigger site of atrial fibrillation. Circulation 122: 109-118, 2010. 